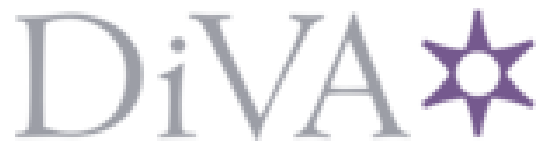

http://www.diva-portal.org

This is the published version of a paper published in ACS Catalysis.

Citation for the original published paper (version of record):

Erbing, E., Sanz-Marco, A., Vazquez-Romero, A., Malmberg, J., Johansson, M J. et al. (2018)

Base- and Additive-Free Ir-Catalyzed ortho-Iodination of Benzoic Acids: Scope and Mechanistic Investigations

ACS Catalysis, 8(2): 920-925

https://doi.org/10.1021/acscatal.7bo2987

Access to the published version may require subscription.

N.B. When citing this work, cite the original published paper.

Reprinted with permission of ACS Catalysis. Copyright 2018 American Chemical Society

Permanent link to this version:

http://urn.kb.se/resolve?urn=urn:nbn:se:su:diva-153631 


\title{
Base- and Additive-Free Ir-Catalyzed ortho-Iodination of Benzoic Acids: Scope and Mechanistic Investigations
}

\author{
Elis Erbing, ${ }^{\dagger, \perp}$ Amparo Sanz-Marco, ${ }^{\dagger, \perp}$ Ana Vázquez-Romero, ${ }^{\dagger}$ Jesper Malmberg, ${ }^{\ddagger}$ Magnus J. Johansson, ${ }^{\S}$ \\ Enrique Gómez-Bengoa," and Belén Martín-Matute*,† \\ ${ }^{\dagger}$ Department of Organic Chemistry, Stockholm University, Stockholm 10691, Sweden \\ ${ }^{\ddagger}$ RIA iMed, Medicinal Chemistry, AstraZeneca R\&D, Mölndal 43183, Sweden \\ ${ }^{\S}$ CVMD iMed, Medicinal Chemistry, AstraZeneca R\&D, Mölndal 43183, Sweden \\ "Departamento de Química Orgánica I, Universidad del País Vasco/UPV-EHU, Manuel de Lardizabal 3, Donostia-San Sebastián \\ 20018, Spain
}

\section{Supporting Information}

ABSTRACT: A protocol for the $\mathrm{C}-\mathrm{H}$ activation/iodination of benzoic acids catalyzed by a simple iridium complex has been developed. The method described in this paper allows the orthoselective iodination of a variety of benzoic acids under extraordinarily mild conditions in the absence of any additive or base in 1,1,1,3,3,3-hexafluoroisopropanol as the solvent. The iridium catalyst used tolerates air and moisture, and selectively gives ortho-iodobenzoic acids with high conversions. Mechanistic investigations revealed that an $\operatorname{Ir}(\mathrm{III}) / \operatorname{Ir}(\mathrm{V})$ catalytic cycle operates, and that the unique properties of HFIP enables the $\mathrm{C}-\mathrm{H}$ iodination using the carboxylic moiety as a directing group. KEYWORDS: C-H iodination, benzoic acids, iridium catalysis, 1,1,1,3,3,3-hexafluoroisopropanol, hydrogen bonding

\section{INTRODUCTION}

Transition-metal-directed activation of inert $\mathrm{C}-\mathrm{H}$ bonds is one of the most efficient ways to introduce functional groups into organic molecules. The combined use of molecules bearing directing groups with the aid of transition-metal catalysts enables the regioselective activation and functionalization of particular $\mathrm{C}-\mathrm{H}$ bonds. ${ }^{1}$

Compounds containing aromatic halides are important building blocks that are ubiquitous in synthetic organic chemistry laboratories. They play pivotal roles in drug and natural-product syntheses. ${ }^{2}$ Furthermore, aromatic bromides and iodides have been extensively used in cross-coupling ${ }^{3}$ and in Grignard reactions. ${ }^{4}$ The functionalization of aromatic compounds with halides through the direct activation of C$\mathrm{H}$ bonds is a straightforward way to obtain halogenated aromatics. The first examples have been reported only in the past decade and were limited to the use of strong, nitrogencontaining directing groups, using palladium catalysis. ${ }^{5} \mathrm{We}$ have also recently reported a heterogeneous $\mathrm{Pd}$ catalyst that halogenates nitrogen-functionalized aromatics. ${ }^{6}$ More recently, different arenes bearing several directing groups, including amides, ketones, and even carbamates could be halogenated in the ortho position by transition metal catalysts. ${ }^{7-9}$ In this context, Nicholls and co-workers ${ }^{9 \mathrm{~h}}$ reported the only example for this transformation employing an Ir catalyst. They described the ortho-halogenation of acetanilides employing $\left[\mathrm{Cp}^{*} \mathrm{IrCl}_{2}\right]_{2}$.

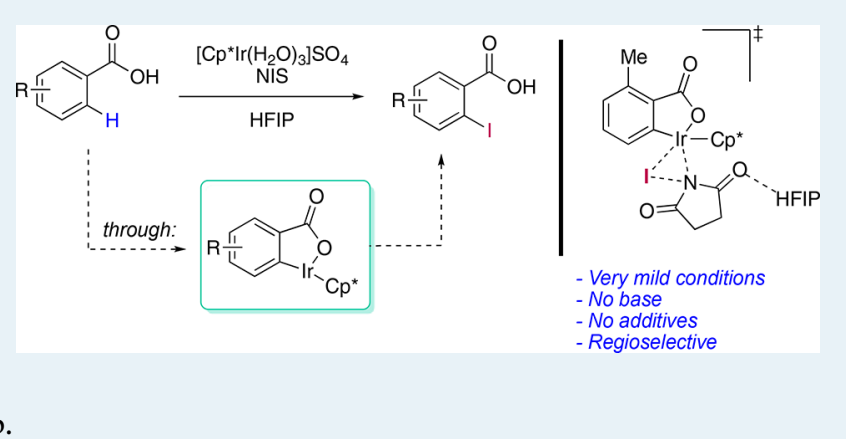

The use of catalytic amounts of Boc- ${ }_{\mathrm{L}}$-Phe and $\mathrm{AgNTf}_{2}$ were necessary to obtain high yields and good regiocontrol.

Carboxylic acids are ubiquitous in natural products. ${ }^{10}$ However, their use as ortho-directing groups in reactions involving the activation of $\mathrm{C}-\mathrm{H}$ bonds has been challenging in terms of yields and selectivity. This is partly due to that in the absence of catalyst, the carboxylic acid moiety is a metadirecting group. This is not the case with for example anilines and derivatives, ${ }^{9 h}$ which direct the functionalization to the ortho and para positions even in the absence of catalysts. During the past few years, however, this field has experienced significant development, ${ }^{11}$ and a variety of methods to construct $\mathrm{C}-\mathrm{C}$ and $\mathrm{C}-\mathrm{N}$ bonds have been described using $\mathrm{Pd},{ }^{12} \mathrm{Ru},{ }^{13}$ and $\mathrm{Rh}^{14}$ With regard to the use of iridium catalysts, Satoh and Miura, ${ }^{15}$ and Ison ${ }^{16}$ reported the oxidative coupling reaction of benzoic acids with alkynes, yielding naphthalenes and isocoumarines. Very recently, Zeng's group reported the $o$-alkynylation of carboxylic acids using excess of $\mathrm{KHCO}_{3} .{ }^{17}$ Gooßen has described the $o$-arylation of carboxylic acids with arenediazonium salts in the presence of $\mathrm{Ag}_{2} \mathrm{CO}_{3}$ and $\mathrm{Li}_{2} \mathrm{CO}_{3}{ }^{18}$ Iridiumcatalyzed ortho- $\mathrm{C}-\mathrm{H}$ amidation of benzoic acids with sulfonyl azides using $\mathrm{AgNTf}_{2}, \mathrm{AcOH}$, and $\mathrm{Li}_{2} \mathrm{CO}_{3}$ as additives was described by Cui and co-workers. ${ }^{19}$

Received: September 1, 2017

Revised: December 12, 2017

Published: December 12, 2017 
The introduction of halides into benzoic acids through $\mathrm{C}-\mathrm{H}$ activation has been, however, quite limited, despite the potential utility of such substrates. ${ }^{11}$ There is only one report, by $\mathrm{Yu}$ and co-workers, that describes the ortho-iodination of carboxylic acids, ${ }^{20}$ where $\mathrm{Pd}(\mathrm{OAc})_{2}$ is used in the presence of superstoichiometric amounts of IOAc. This method afforded good yields at $100{ }^{\circ} \mathrm{C}$ in $36 \mathrm{~h}$. The direct $\mathrm{C}-\mathrm{H}$ iodination of benzoic acids under milder reaction conditions would allow the introduction of iodide at a late stage, and a $\mathrm{C}-\mathrm{H}$ iodination protocol avoiding the use of additives (i.e., bases, silver salts, or strong oxidants) would significantly increase the functionalgroup tolerance as well as the atom economy.

Our group has gained extensive knowledge about the selective transition-metal-catalyzed halogenation of molecules. $^{21}$ We have reported 1,3-hydrogen shift/halogenation protocols for aliphatic and aromatic allylic alcohols under mild conditions using iridium catalysis. In this paper, we report a mild, efficient, and extraordinarily simple method for the selective ortho- $\mathrm{C}-\mathrm{H}$ iodination of benzoic acids catalyzed by a $\mathrm{P} / \mathrm{N}$-ligandless $\operatorname{Ir}(\mathrm{III})$ catalyst (Scheme 1). Experimental and theoretical investigations elucidating the mechanism and the unique role of the solvent are also presented.

Scheme 1. C-H Iodination of Benzoic Acids

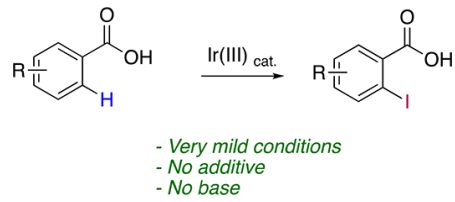

\section{RESULTS AND DISCUSSION}

We started using 2-methylbenzoic acid (1a) as the model substrate with NIS ( $\mathrm{N}$-iodosuccinimide) as the halogenating
Scheme 2. Robustness Screening Test

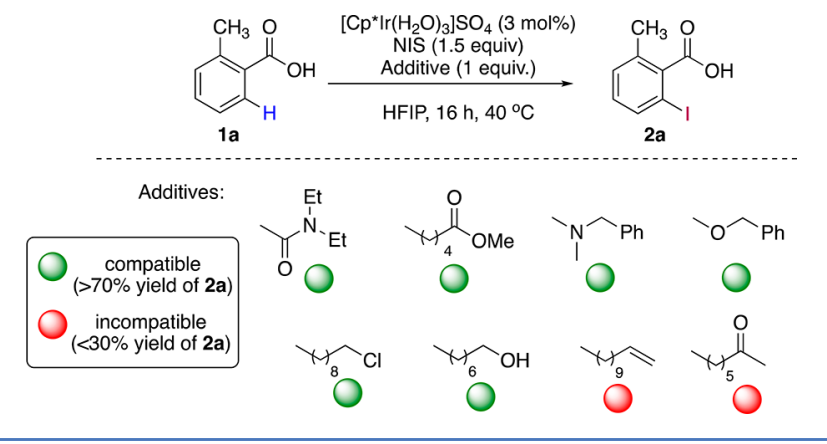

agent and investigated the influence of a number of parameters (Tables 1 and S1 of the Supporting Information, SI). Due to their excellent performance in halogenation reactions under both air and water, ${ }^{21}$ and inspired by the reaction conditions reported by Gooßen ${ }^{18}$ for $\mathrm{C}-\mathrm{H}$ arylations, we investigated complexes of the general structure [Cp*Ir(III)]. Glorius has also reported excellent results using related $\left[\mathrm{Cp} * \mathrm{Rh}(\mathrm{III}) \mathrm{X}_{2}\right]$ complexes in the $\mathrm{C}-\mathrm{H}$ halogenation of other aromatic compounds. ${ }^{8}$

When 1a was treated with 3 equiv of NIS and $\left[\mathrm{Cp}^{*} \mathrm{IrCl}_{2}\right]_{2}$ in the presence of catalytic amounts of $\mathrm{AgBF}_{4}$ and $\mathrm{NaOAc}$ (Table 1 ), in acetone at $60{ }^{\circ} \mathrm{C}$, a $25 \%$ yield of $2 \mathbf{b}$ was obtained (entry 1). Other solvents were tested under otherwise identical conditions (Table S1), but the best results were obtained in HFIP (1,1,1,3,3,3-hexafluoroisopropanol), which gave 2 a in $86 \%$ yield (entry 2$)$. With chloride-free $\left(\left[\mathrm{Cp} * \operatorname{Ir}\left(\mathrm{H}_{2} \mathrm{O}\right)_{3}\right] \mathrm{SO}_{4}\right)$ II, easily prepared from $\mathrm{I}^{22}$ the yield increased to $90 \%$ (entry 3 ). The temperature could be lowered to $40{ }^{\circ} \mathrm{C}$ without compromising the yield (entry 4 ). In the absence of additives, the yield did not decrease, giving $2 \mathrm{a}$ in $88 \%$ yield (entry 5 ). Furthermore, with only 1.5 equiv of NIS, 2a was formed in nearly quantitative yield (entry 6 ). Intrigued by these excellent

Table 1. Screening of the Reaction Conditions ${ }^{a}$

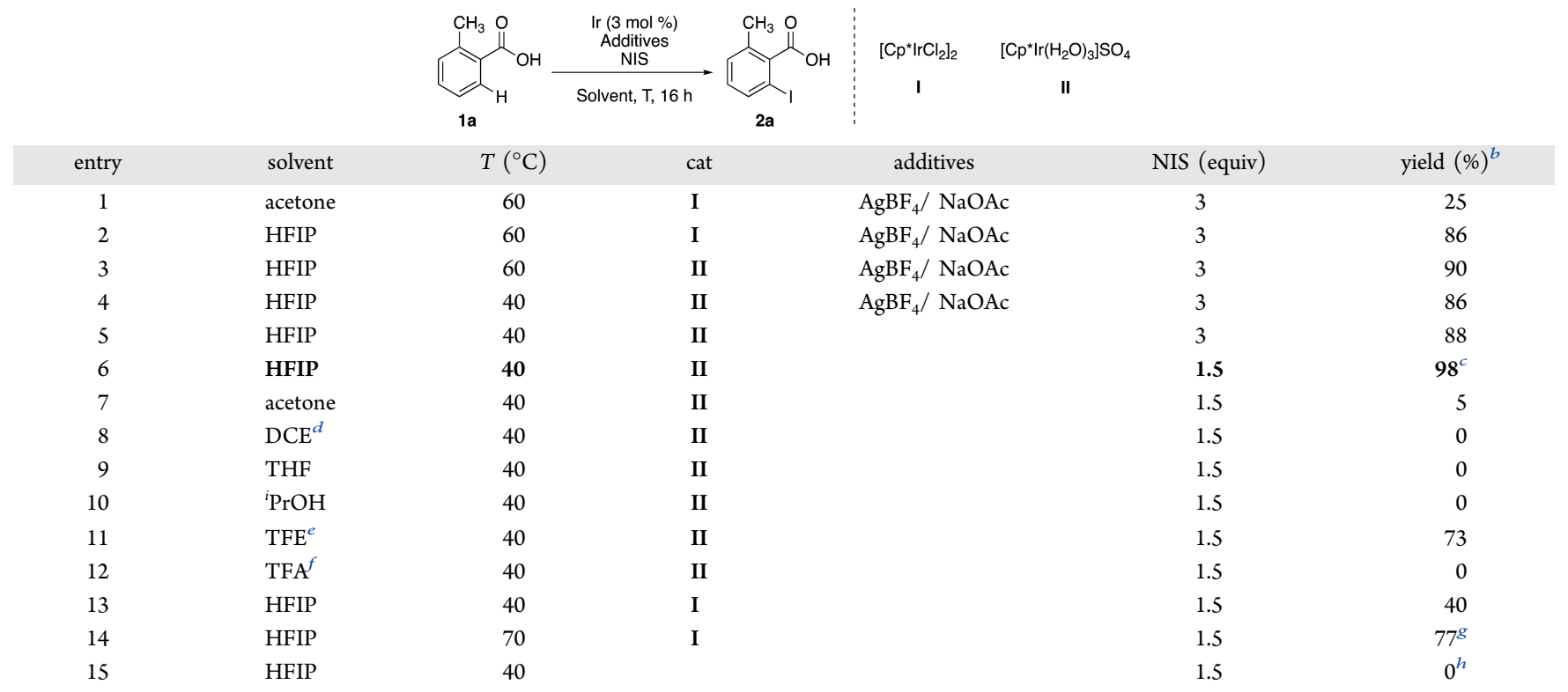

${ }^{a}$ Unless otherwise noted, all experiments were carried out under air atmosphere on $0.15 \mathrm{mmol}$ scale of $1 \mathrm{a}$ and $0.1 \mathrm{M}$. AgBF 4 (20 mol \%), $\mathrm{NaOAc}$ $(30 \mathrm{~mol} \%)$ for $16 \mathrm{~h} .{ }^{b}$ Determined by ${ }^{1} \mathrm{H}$ NMR spectroscopy against an internal standard $(1,2,4,5$-tetrachloro-3-nitrobenzene $) .{ }^{c}$ Isolated yield. ${ }^{d}$ DCE $=1,2$-dichloroethane. ${ }^{e} \mathrm{TFE}=2,2,2$-trifluoroethanol. ${ }^{f_{\mathrm{TFA}}}=$ trifluoroacetic acid. ${ }^{g}$ Yield of $2 \mathrm{a}$ after $48 \mathrm{~h}$. The reminder being $15 \%$ of starting material and $8 \%$ of unidentified byproducts. ${ }^{h}$ Iodination in meta position in $56 \%$ yield after $18 \mathrm{~h}$. 
Scheme 3. Scope of the Reaction ${ }^{a}$

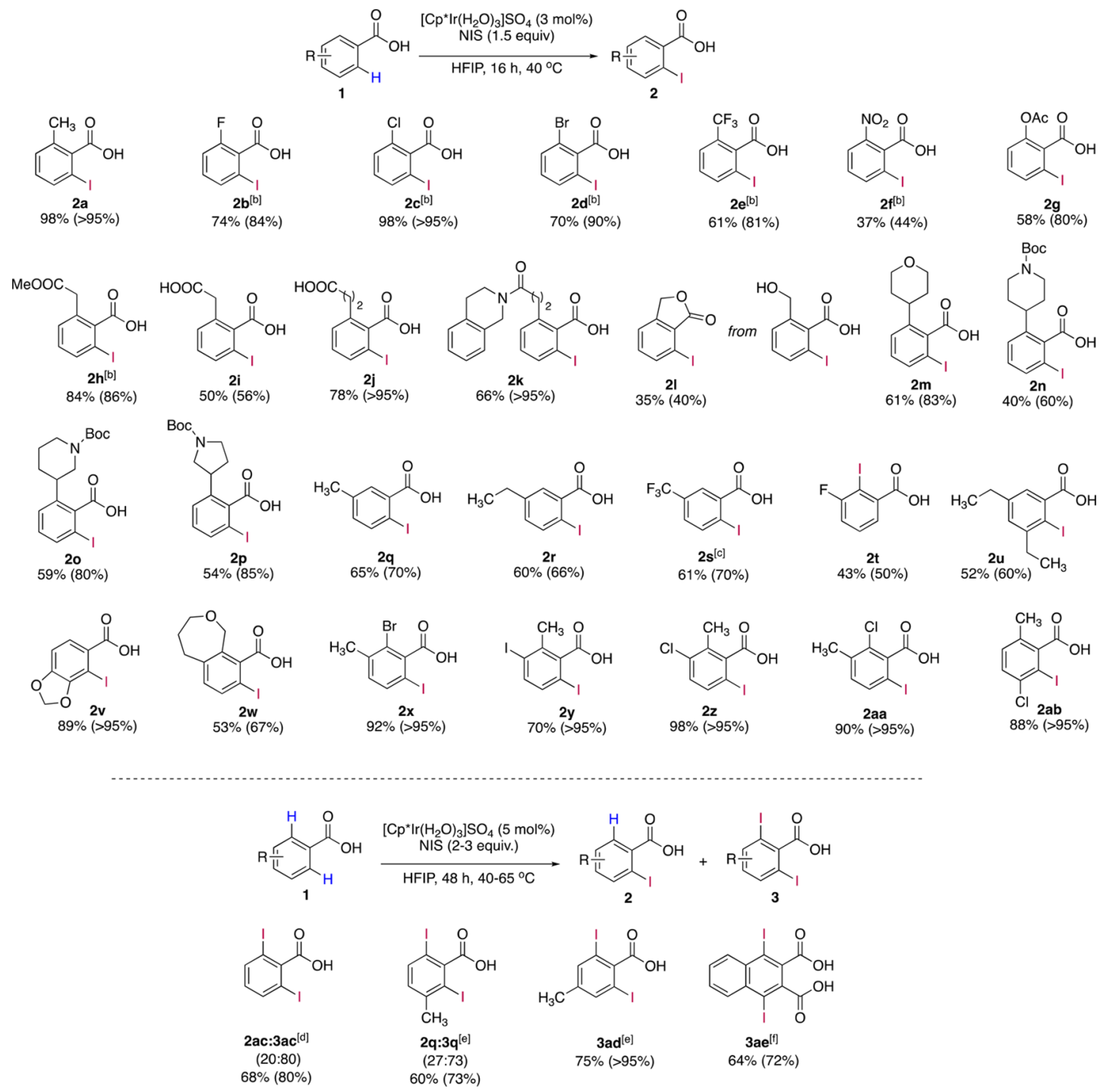

${ }^{a}$ Isolated yields (yield by ${ }^{1} \mathrm{H}$ NMR spectroscopy in parentheses). ${ }^{b}$ The reaction was carried out at $60{ }^{\circ} \mathrm{C}$. ${ }^{c}$ The reaction was carried out at $60{ }^{\circ} \mathrm{C}$ using a catalyst loading of $5 \mathrm{~mol} \%$. ${ }^{d}$ At $65{ }^{\circ} \mathrm{C}$ using 2 equiv of NIS. ${ }^{e}$ At $65{ }^{\circ} \mathrm{C}$ using 3 equiv of NIS. ${ }^{f}$ At $40{ }^{\circ} \mathrm{C}$ using 3 equiv of NIS.

results without additives, we wondered whether the solvent had a significant impact on the reaction. In acetone, 1,2-dichloroethane (DCE), or THF no product was obtained at $40{ }^{\circ} \mathrm{C}$ (entries 7-9). Interestingly, ${ }^{i} \mathrm{PrOH}$ did not yield any product (entry 10). In contrast, 2,2,2-trifluoroethanol (TFE), gave a $73 \%$ yield (entry 11 ). Thus, protic solvents with low $\mathrm{p} K_{\mathrm{a}}$ values such as HFIP $\left(\mathrm{p} K_{\mathrm{a}}=9.3\right)$ or TFE $\left(\mathrm{p} K_{\mathrm{a}}=12.4\right)$ give the best results. In more acidic solvents, such as $\mathrm{CF}_{3} \mathrm{CO}_{2} \mathrm{H}$ (TFA) $\left(\mathrm{p} K_{\mathrm{a}}\right.$ $=0.2$ ) the activity was compromised (entry 12). Under the optimal conditions, we evaluated again the catalytic activity of chloride complex I, which afforded $2 \mathrm{a}$ in only $40 \%$ yield after $16 \mathrm{~h}$ (entry 13). Upon increasing the temperature to $70^{\circ} \mathrm{C}, 2 \mathrm{a}$ was obtained in $77 \%$ yield after $48 \mathrm{~h}$, together with $15 \%$ of starting material, the reminder being unidentified byproducts (entry 14). A control experiment in the absence of catalyst resulted in iodination of the meta position in 56\% yield (entry 15). This background meta-iodination is completely suppressed under the catalytic conditions reported here. All reactions were carried out under an atmosphere of air.
The compatibility of the reaction conditions with different functional groups was preliminarily evaluated by performing a robustness-screening test ${ }^{23}$ (Scheme 2). Thus, the iridiumcatalyzed $\mathrm{C}-\mathrm{H}$ iodination reaction in the presence of a variety of functionalized molecules. Under the optimal conditions (Table 1, entry 6), amines, amides, ethers, esters, alcohols, and halogenated compounds were well tolerated, and $\mathbf{2 a}$ was obtained in good yield (Scheme 2 and Table S2). However, the reaction is noncompatible with double or triple bonds, nor with aldehydes or ketones (see SI for further details).

On the basis of the results from the robutness-screening test, the scope of the reaction was investigated. Iodinated products from $o$-substituted benzoic acids $(\mathbf{1} \mathbf{a}-\mathbf{1} \mathbf{p})$ were obtained in very high yields (Scheme 3 ). Among these, substrates bearing halogens substituents $(\mathbf{1 b}-\mathbf{1 d})$ gave yields from 70 to $98 \%$. Lower yields were obtained for the more electron-withdrawing $\mathrm{CF}_{3}$ and $\mathrm{NO}_{2}(\mathbf{1 e}-\mathbf{1 f})$ [the lower reactivity of electron-poor carboxylic acids 1e and 1f, when compared to that of $1 \mathrm{a}$, can be explained as a result of a decreased electron density on the iridium (III) center, reducing its ability to effectively undergo 
Scheme 4. Experimental Mechanistic Studies

a)<smiles>Cc1ccccc1C(=O)O</smiles>
$\left[\mathrm{Cp}^{*} \mathrm{Ir}\left(\mathrm{H}_{2} \mathrm{O}\right)_{3}\right] \mathrm{SO}_{4}$ (1.1 equiv.)
$\stackrel{\mathrm{NaOAc}(2 \text { equiv. })}{\stackrel{\mathrm{DMSO}(2 \text { equiv. })}{\mathrm{MeOH}, 60^{\circ} \mathrm{C}, 1 \mathrm{~h}}}$ $90 \%$ yield

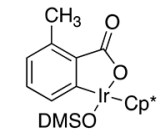

6a

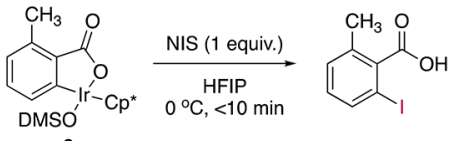

$6 a$
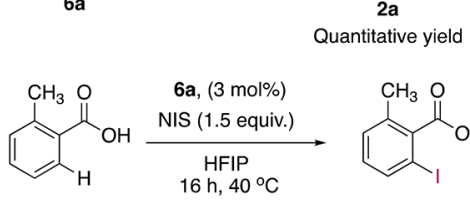

1a $92 \%$ yield

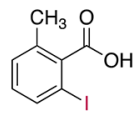

2a

d)

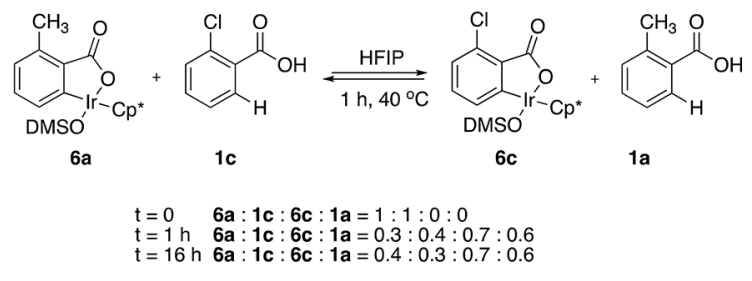

Scheme 5. Iodination of 6a in Different Solvents

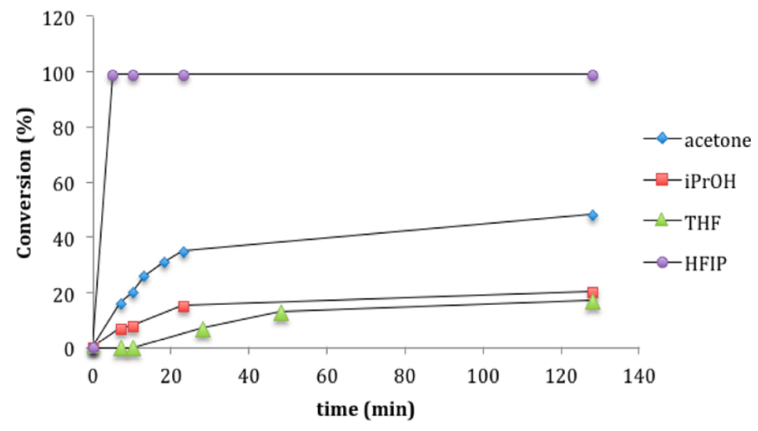

Scheme 6. KIE Determination

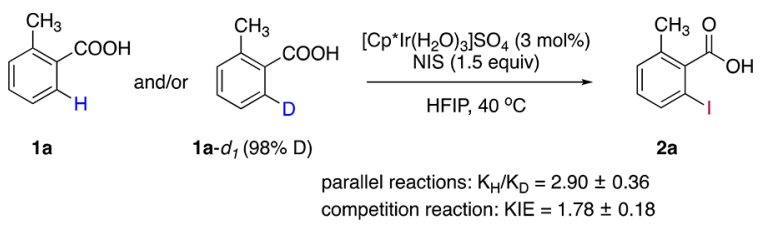

oxidative addition to form the $\operatorname{Ir}(\mathrm{V})$ intermediate, as confirmed computationally (see SI)]. Alcohols, ethers, esters, carboxylic acids (phenylacetic acid under the optimal reaction conditions gave only $10 \%$ yield of 2-iodophenylacetic acid; the low ability of the $\mathrm{CH}_{2} \mathrm{CO}_{2} \mathrm{H}$ functional group to direct the iodination enables selective formation of $2 \mathbf{i}$ from dicarboxylic acid $\mathbf{1 i}$ ), amines, and amides are well tolerated in agreement with the robustness test, and $\mathbf{2 g}-\mathbf{2} \mathbf{p}$ were obtained in high yields showing the broad functional group tolerance of this methodology. Selectively monoiodinated products were obtained with meta-substituted 1q-1t. Highly substituted benzoic acids $\mathbf{1} \mathbf{u}-$ 1ab were also iodinated. Full control over the regioselectivity was also obtained in substrates with two ortho- $\mathrm{C}-\mathrm{H}$ positions $(\mathbf{2 q - v})$ (in contrast with the work reported by $\mathrm{Yu}$ and coworkers, the iridium system reported here affords selectively monoiodinated products from meta-substituted benzoic acids; this selectivity may be due to the milder reaction conditions used here). Benzoic acid itself gave a mixture of mono- and diiodinated products $2 \mathrm{ac}$ and 3ac, respectively. By increasing the catalyst loading and the number of equivalents of NIS, 3ac was obtained as the major product. Under these conditions, $\mathbf{1 q}$ gave diiodinated $\mathbf{3 q}$, and $\mathbf{1}$ ad and $\mathbf{1 a e}$, the latter with two acid groups, were diiodinated in very good yields.

Mechanistic investigations were then undertaken. First, we studied whether iridacycles in oxidation state +3 are intermediates. When 1a was treated with a superstoichiometric amount of II (1.1 equiv) at $40{ }^{\circ} \mathrm{C}$ in HFIP, an iridacyclic structure was formed and characterized by ${ }^{1} \mathrm{H}$ NMR spectroscopy (see SI). The iridacycle thus prepared could not be isolated. We therefore prepared DMSO-stabilized iridacycle 6a instead (Scheme $4 \mathrm{a}) .{ }^{16}$ Reaction of $6 \mathrm{a}$ with NIS at $0{ }^{\circ} \mathrm{C}$ gave, within a few minutes, $\mathbf{2 a}$ (Scheme $4 \mathrm{~b}$ ). Furthermore, when $\mathbf{6 a}$ was used as a catalyst (Scheme 4c), the results did not differ from those obtained with II. The reversibility of the $\mathrm{C}-\mathrm{H}$ activation was confirmed when a 1:1 mixture of iridacycle 6a and 2-chlorobenzoic acid 1c was reacted in HFIP at $40{ }^{\circ} \mathrm{C}$ (Scheme $4 \mathrm{~d}$ and SI). After $1 \mathrm{~h}$, a mixture of both carboxylic acids $\mathbf{1 a}$ and $\mathbf{1 c}$, as well as iridacycles, $\mathbf{6} \mathbf{a}$ and $\mathbf{6 c}$ was observed. Similar results were obtained when $\mathbf{6 a}$ was reacted with carboxylic acids 1e or 1f (see SI, S27).

When comparing the iodination rates of $\mathbf{6 a}$ in different solvents, it was observed that the reaction was significantly accelerated in HFIP (Scheme 5).

A KIE (kinetic isotope effect) of $2.90 \pm 0.36$ was obtained when comparing the rate of 1a to that of 1 a- $d_{1}$ (Scheme 6 and Figures S5 and S6) under noncompetition conditions. The reversibility of the $\mathrm{C}-\mathrm{H}$ activation (vide supra, Scheme $4 \mathrm{~d}$ ) is in agreement with the magnitude of this KIE. The high iodination rate of iridacycle $\mathbf{6 a}$ (Scheme $4 b$ ), together with the $\mathrm{KIE}$, indicates that the $\mathrm{C}-\mathrm{H}$ bond is broken in the rate-limiting step (rls).

To obtain further information, DFT calculations were carried out using M06/6-311G** (SDD for Ir, I) with a solvation model (IEFPCM, solvent $=$ TFE). Initially, taking the iridacycle SM as the reference, and in the absence of HFIP, activation energies of $21.8,25.6$, and $23.5 \mathrm{kcal} / \mathrm{mol}$ were computed for the oxidative addition, reductive elimination and $\mathrm{C}-\mathrm{H}$ activation, respectively (SI). The reductive elimination is the slowest step $(25.6 \mathrm{kcal} / \mathrm{mol})$, which is inconsistent with the C$\mathrm{H}$ bond being broken in the rls.

These data are intriguing and could be related with the fact that the experimental results were substantially better when the reactions were carried out in HFIP, as opposed to other solvents (Table 1 and Scheme 5). The similarity of the activation energies of the three steps and the crucial role of HFIP suggest a complex mechanism involving a change in rls depending on the reaction conditions. It has been demonstrated that fluorinated alcohols can be exceptional reaction media for various transformations, including $\mathrm{C}-\mathrm{H}$ activations. ${ }^{24}$ Therefore, the cycle was recomputed in the presence of HFIP, which can form $\mathrm{H}$-bonds with $\mathrm{NIS},{ }^{25}$ facilitating or disabling the different steps of the reaction. The $E_{\mathrm{a}}$ of the three consecutive steps now became $21.4,20.0$, and $23.6 \mathrm{kcal} / \mathrm{mol}$, respectively (Figure 1). The electron withdrawing effect of the $\mathrm{H}$-bonding with $\mathrm{HFIP}^{26}$ was found to preferentially destabilize $\operatorname{Ir}(\mathrm{V})$ intermediate INT-2 (resting state in the absence of HFIP, see SI), thus reducing the $E_{\mathrm{a}}$ of the reductive elimination (TS$\mathrm{RE}$ ), and accelerating the reaction. This agrees well with the 


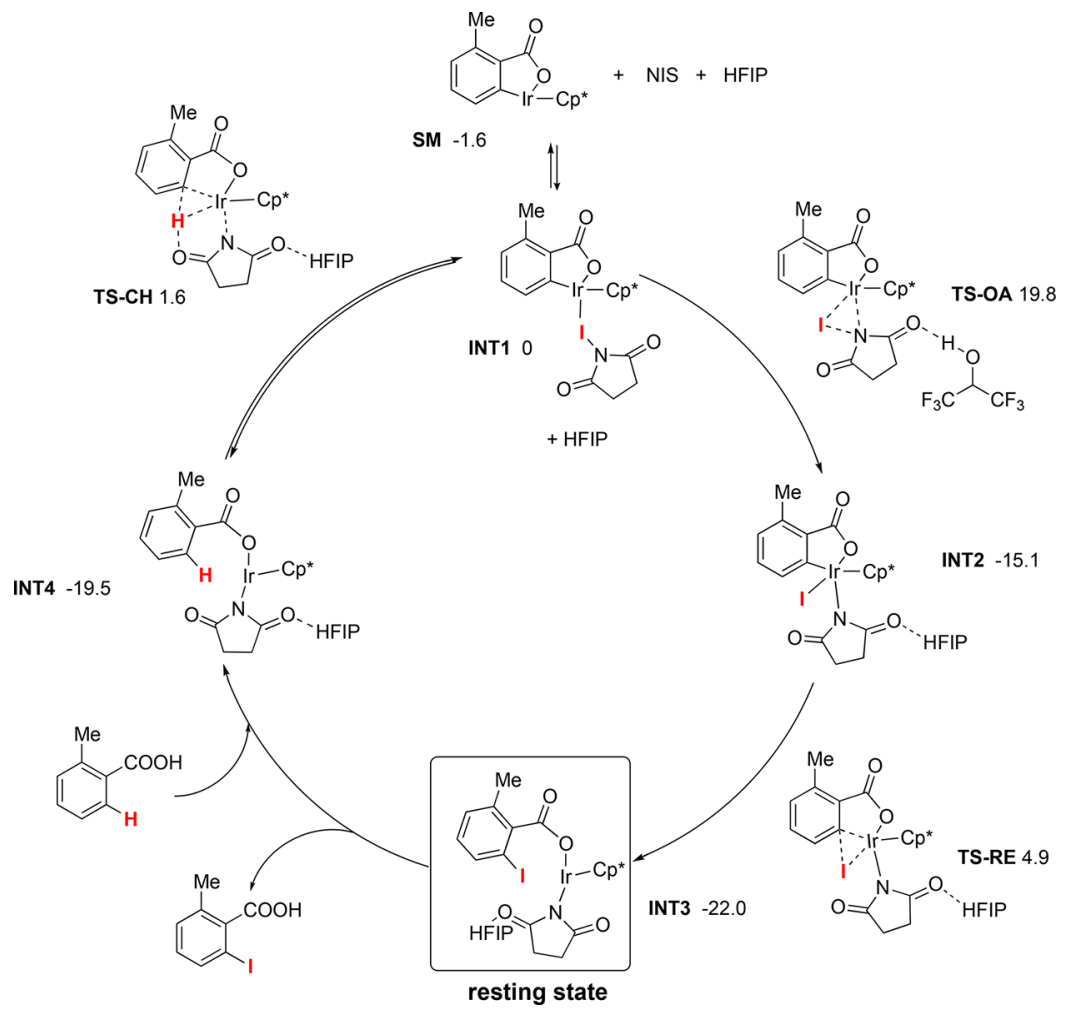

Figure 1. Catalytic cycle. The energy values correspond to free energies in $\mathrm{kcal} / \mathrm{mol}$.

kinetic profile of the reaction of $\mathbf{6 a}$ with NIS in different solvents (Scheme 5 and Table 1). The $\mathrm{C}-\mathrm{H}$ activation step then becomes the rls (TS-CH, $23.6 \mathrm{kcal} / \mathrm{mol}$ ) and occurs via a concerted metalation-deprotonation (CMD) pathway, ${ }^{27}$ agreeing well with the excellent results obtained in the absence of any base, and explaining the superior activity in HFIP as the solvent (Table 1). Futher attempts to support the proposed mechanism resulted in the characterization by ${ }^{1} \mathrm{H}$ NMR spectroscopy of an additional iridacycle, formed exclusively upon addition of NIS, and that may be assigned to INT2 (see SI). An alternative mechanism without involving $\operatorname{Ir}(\mathrm{V})$ intermediates in which the iridacycle species are directly iodinated, was also considered. However, we could not locate any effective TS below $30 \mathrm{kcal} / \mathrm{mol}$ for that process.

\section{CONCLUSIONS}

In summary, a very efficient catalytic method for the iodination of benzoic acids has been developed. A simple Ir(III) complex is used, which, under very mild reaction conditions and in the absence of any additive or base, selectively gives $o$-iodinated carboxylic acids in excellent yields when HFIP is used as the solvent. Air and moisture are well tolerated. The mechanism for this mild $\mathrm{C}-\mathrm{H}$ iodination involves a rate-limiting metalation, followed by iodination through an $\operatorname{Ir}(\mathrm{III}) / \mathrm{Ir}(\mathrm{V})$ catalytic cycle. Most importantly, we present for the first time strong evidence explaining the unique role of the solvent HFIP in this $\mathrm{C}-\mathrm{H}$ activation; upon formation of $\mathrm{H}$-bonds, HFIP is able to lower the activation energy of the reductive elimination step. These studies may contribute to develop an understanding of the beneficial effect of using HFIP as the solvent in catalytic reactions.

\section{ASSOCIATED CONTENT}

S Supporting Information

The Supporting Information is available free of charge on the ACS Publications website at DOI: 10.1021/acscatal.7b02987.

Experimental procedures and full characterization of the products (PDF)

\section{AUTHOR INFORMATION}

\section{Corresponding Author}

*E-mail: belen.martin.matute@su.se (B.M.-M.).

ORCID $\odot$

Belén Martín-Matute: 0000-0002-7898-317X

\section{Author Contributions}

${ }^{\perp}$ E.E. and A.S.-M. contributed equally to this work.

Notes

The authors declare no competing financial interest.

\section{ACKNOWLEDGMENTS}

Dedicated to Prof. J.-E. Bäckvall on the occasion of his $70^{\text {th }}$ birthday. This project was supported by the Swedish Research Council through Vetenskapsrådet and Formas, the Knut and Alice Wallenberg Foundation, and AstraZeneca. A.S.-M. was supported by the Generalitat Valenciana and Universitat de València (Spain) through a postdoctoral grant, and A.V.-R. was supported by the Wenner-Gren Foundation through a postdoctoral grant. We thank IZO-SGI SGIker of UPV/EHU for human and technical support. We also thank Dr A. Bermejo Gomez for helpful discussions.

\section{REFERENCES}

(1) For recent reviews on $\mathrm{C}-\mathrm{H}$ activation, see: (a) Giri, R.; Shi, B.F.; Engle, K. M.; Maugel, N.; Yu, J.-Q. Chem. Soc. Rev. 2009, 38, 3242- 
3272. (b) Chen, X.; Engle, K. M.; Wang, D.-H.; Yu, J.-Q. Angew. Chem., Int. Ed. 2009, 48, 5094-5115. (c) Wencel-Delord, J.; Dröge, T.; Liu, F.; Glorius, F. Chem. Soc. Rev. 2011, 40, 4740-4761. (d) Engle, K. M.; Mei, T.-S.; Wasa, M.; Yu, J.-Q. Acc. Chem. Res. 2012, 45, 788-802. (e) Gensch, T.; Hopkinson, M. N.; Glorius, F.; WencelDelord, J. Chem. Soc. Rev. 2016, 45, 2900-2936.

(2) (a) Winterton, N. Green Chem. 2000, 2, 173-225. (b) Gribble, G. W. J. Chem. Educ. 2004, 81, 1441-1449. (c) Liu, C.; Zhang, B. Chem. Rec. 2016, 16, 667-687.

(3) (a) Fairlamb, I. J. S. Chem. Soc. Rev. 2007, 36, 1036-1045. (b) de Meijere, A.; Bräse, S.; Oestreich, M. Metal Catalyzed Cross Coupling Reactions and More; Wiley: Weinheim, 2013; Vol. 3, pp 1329-1348.

(4) Silverman, G. S.; Rakita, P. E. Methods of Grignard Reagent Preparation in Handbook of Grignard Reagents; Marcel Dekker: New York, 1996; pp 9-20.

(5) (a) Kalyani, D.; Dick, A. R.; Anani, W. Q.; Sanford, M. S. Org. Lett. 2006, 8, 2523-2526. (b) Kalyani, D.; Dick, A. R.; Anani, W. Q.; Sanford, M. S. Tetrahedron 2006, 62, 11483-11498. (c) Chen, X.; Hao, X.-S.; Goodhue, C. E.; Yu, J.-Q. J. Am. Chem. Soc. 2006, 128, 6790-6791. (d) Whitfield, S. R.; Sanford, M. S. J. Am. Chem. Soc. 2007, 129, 15142-15143. (e) Zhao, X.; Dimitrijević, E.; Dong, V. M. J. Am. Chem. Soc. 2009, 131, 3466-3467. (f) Kakiuchi, F.; Kochi, T.; Mutsutani, H.; Kobayashi, N.; Urano, S.; Sato, M.; Nishiyama, S.; Tanabe, T. J. Am. Chem. Soc. 2009, 131, 11310-11311. (g) Tian, O.; Chen, X.; Liu, W.; Wang, Z.; Shi, S.; Kuang, C. Org. Biomol. Chem. 2013, 11, 7830-7833.

(6) Pascanu, V.; Carson, F.; Solano, M. V.; Su, J.; Zou, X.; Johansson, M. J.; Martín-Matute, B. Chem. - Eur. J. 2016, 22, 3729-3737.

(7) (a) Mei, T.-S.; Wang, D.-H.; Yu, J.-Q. Org. Lett. 2010, 12, 31403143. (b) Chan, K. S. L.; Wasa, M.; Wang, X.; Yu, J.-Q. Angew. Chem., Int. Ed. 2011, 50, 9081-9084. (c) Wang, X.-C.; Hu, Y.; Bonacorsi, S.; Hong, Y.; Burrell, R.; Yu, J.-Q. J. Am. Chem. Soc. 2013, 135, 1032610329. (d) Chu, L.; Xiao, K.-J.; Yu, J.-Q. Science 2014, 346, 451-455. (e) Dastbaravardeh, N.; Toba, T.; Farmer, M. E.; Yu, J.-Q. J. Am. Chem. Soc. 2015, 137, 9877-9884.

(8) (a) Schröder, N.; Wencel-Delord, J.; Glorius, F. J. Am. Chem. Soc. 2012, 134, 8298-8301. (b) Kuhl, N.; Schroder, N.; Glorius, F. Org. Lett. 2013, 15, 3860-3863. (c) Yu, D. G.; Gensch, T.; de Azambuja, F.; Vásquez-Cespedes, S.; Glorius, F. J. Am. Chem. Soc. 2014, 136, 17722-17725. (d) Schröder, N.; Lied, F.; Glorius, F. J. Am. Chem. Soc. 2015, 137, 1448-1451. (e) Lied, F.; Lerchen, A.; Knecht, T.; MückLichtenfeld, C.; Glorius, F. ACS Catal. 2016, 6, 7839-7843.

(9) (a) Wan, X.; Ma, Z.; Li, B.; Zhang, K.; Cao, S.; Zhang, S.; Shi, Z. J. Am. Chem. Soc. 2006, 128, 7416-7417. (b) Fier, P. S.; Hartwig, J. F. Science 2013, 342, 956-960. (c) Sarkar, D.; Melkonyan, F. S.; Gulevich, A. V.; Gevorgyan, V. Angew. Chem., Int. Ed. 2013, 52, 10800-10804. (d) Du, B.; Jiang, B. X.; Sun, P. J. Org. Chem. 2013, 78, 2786-2791. (e) Hwang, H.; Kim, J.; Jeong, J.; Chang, S. J. Am. Chem. Soc. 2014, 136, 10770-10776. (f) Wang, L. H.; Ackermann, L. Chem. Commun. 2014, 50, 1083-1085. (g) Khan, B.; Kant, R; Koley, D. Adv. Synth. Catal. 2016, 358, 2352-2358. (h) Kathiravan, S.; Nicholls, I. A. Chem. - Eur. J. 2017, 23, 7031-7036.

(10) (a) Ballatore, C.; Huryn, D. M.; Smith, A. B., III ChemMedChem 2013, 8, 385-395. (b) Liang, D.; Hao, Z.-Y.; Liu, Y.-F.; Luo, H.; Wang, Y.; Zhang, C.-L.; Zhang, O.-J.; Chen, R.-Y.; Yu, D.-Q. J. Asian Nat. Prod. Res. 2013, 15, 59-66. (c) Rosen, B. R.; Simke, L. R.; ThuyBoun, P. S.; Dixon, D. D.; Yu, J.-Q.; Baran, P. S. Angew. Chem., Int. Ed. 2013, 52, 7317-7320.

(11) Drapeau, M. P.; Gooßen, L. Chem. - Eur. J. 2016, 22, 1865418677.

(12) (a) Chiong, H. A.; Pham, Q.-N.; Daugulis, O. J. Am. Chem. Soc. 2007, 129, 9879-9884. (b) Giri, R.; Maugel, N.; Li, J.-J.; Wang, D.-H.; Breazzano, S. P.; Saunders, L. B.; Yu, J.-Q. J. Am. Chem. Soc. 2007, 129, 3510-3511. (c) Wang, D.-H.; Mei, T.-S.; Yu, J.-Q. J. Am. Chem. Soc. 2008, 130, 17676-17677. (d) Cornella, J.; Righi, M.; Larrosa, I. Angew. Chem., Int. Ed. 2011, 50, 9429-9432. (e) Ng, K.-H.; Ng, F.-N.; Yu, W.-Y. Chem. Commun. 2012, 48, 11680-11682. (f) Wu, Z.; Chen, S.; Hu, C.; Li, Z.; Xiang, H.; Zhou, X. ChemCatChem 2013, 5, 28392842. (g) Arroniz, C.; Denis, J. G.; Ironmonger, A.; Rassias, G.;
Larrosa, I. Chem. Sci. 2014, 5, 3509-3514. (h) Zhu, C.; Zhang, Y.; Kan, J.; Zhao, H.; Su, W. Org. Lett. 2015, 17, 3418-3421. (i) Cheng, G.; Li, T.-J.; Yu, J.-Q. J. Am. Chem. Soc. 2015, 137, 10950-10953.

(13) (a) Ackermann, L.; Pospech, J.; Graczyk, K.; Rauch, K. Org. Lett. 2012, 14, 930-933. (b) Warratz, S.; Kornhaa $\beta$, C.; Cajaraville, A.; Niepötter, B.; Stalke, D.; Ackermann, L. Angew. Chem., Int. Ed. 2015, 54, 5513-5517. (c) Biafora, A.; Krause, T.; Hackenberger, D.; Belitz, F.; Gooßen, L. J. Angew. Chem., Int. Ed. 2016, 55, 14752-14755. (d) Bechtoldt, A.; Tirler, C.; Raghuvanshi, K.; Warratz, S.; Kornhaa $\beta$, C.; Ackermann, L. Angew. Chem., Int. Ed. 2016, 55, 264-267. (e) Huang, L.; Weix, D. J. Org. Lett. 2016, 18, 5432-5435. (f) Mei, R; Zhu, C.; Ackermann, L. Chem. Commun. 2016, 52, 13171-13174. (g) Simonetti, M.; Cannas, D. M.; Panigrahi, A.; Kujawa, S.; Kryjewski, M.; Xie, P.; Larrosa, I. Chem. - Eur. J. 2017, 23, 549-553.

(14) (a) Ueura, K.; Satoh, T.; Miura, M. Org. Lett. 2007, 9, 14071409. (b) Qin, X.; Li, Z.; Huang, Q.; Liu, H.; Wu, D.; Guo, Q.; Lan, J.; Wang, R.; You, J. Angew. Chem., Int. Ed. 2015, 54, 7167-7170. (c) Gandeepan, P.; Rajamalli, P.; Cheng, C.-H. Chem. - Eur. J. 2015, $21,9198-9203$.

(15) Ueura, K.; Satoh, T.; Miura, M. J. Org. Chem. 2007, 72, 53625367.

(16) (a) Frasco, D. A.; Lilly, C. P.; Boyle, P. D.; Ison, E. A. ACS Catal. 2013, 3, 2421-2429. (b) Frasco, D. A.; Sommer, R. D.; Ison, E. A. Organometallics 2015, 34, 275-279.

(17) Chen, C.; Liu, P.; Tang, J.; Deng, G.; Zeng, X. Org. Lett. 2017, 19, 2474-2477.

(18) Huang, L.; Hackenberger, D.; Gooßen, L. Angew. Chem., Int. Ed. 2015, 54, 12607-12611.

(19) Wei, M.-E.; Wang, L.-H.; Li, Y.-D.; Cui, X.-L. Chin. Chem. Lett. 2015, 26, 1336-1340.

(20) Mei, T.-S.; Giri, R; Maugel, N.; Yu, J.-Q. Angew. Chem., Int. Ed. 2008, 47, 5215-5219.

(21) (a) Ahlsten, N.; Martín-Matute, B. Chem. Commun. 2011, 47, 8331-8333. (b) Ahlsten, N.; Bermejo Gómez, A.; Martín-Matute, B. Angew. Chem., Int. Ed. 2013, 52, 6273-6276. (c) Gómez, A. B.; Erbing, E.; Batuecas, M.; Vázquez-Romero, A.; Martín-Matute, B. Chem. - Eur. J. 2014, 20, 10703-10709. (d) Vázquez-Romero, A.; Gómez, A. B.; Martín-Matute, B. ACS Catal. 2015, 5, 708-714. (e) Martinez-Erro, S.; Bermejo Gómez, A.; Vázquez-Romero, A.; Erbing, E.; MartínMatute, B. Chem. Commun. 2017, 53, 9842-9845.

(22) For preparation of catalyst II, see: Ogo, S.; Makihara, N.; Watanabe, Y. Organometallics 1999, 18, 5470-5474.

(23) (a) Collins, K. D.; Glorius, F. Nat. Chem. 2013, 5, 597-601. (b) Collins, K. D.; Rühling, A.; Lied, F.; Glorius, F. Chem. - Eur. J. 2014, 20, 3800-3805.

(24) Wencel-Delord, J.; Colobert, F. Org. Chem. Front. 2016, 3, 394400 .

(25) For the activation of NIS with acidic additive, see: Racys, D. T.; Sharif, S. A. I.; Pimlott, S. L.; Sutherland, A. J. Org. Chem. 2016, 81, $772-780$.

(26) For the activation of hypervalent iodine reagent with HFIP via H-bonding, see: Colomer, I.; Batchelor-McAuley, C.; Odell, B.; Donohoe, T. J.; Compton, R. G. J. Am. Chem. Soc. 2016, 138, 88558861.

(27) (a) Lafrance, M.; Rowley, C. N.; Woo, T. K.; Fagnou, K. J. Am. Chem. Soc. 2006, 128, 8754-8756. (b) García-Cuadrado, D.; Braga, A. A. C.; Maseras, F.; Echavarren, A. M. J. Am. Chem. Soc. 2006, 128, 1066-1067. (c) Gorelsky, S. I.; Lapointe, D.; Fagnou, K. J. Am. Chem. Soc. 2008, 130, 10848-10849. (d) Lapointe, D.; Fagnou, K. Chem. Lett. 2010, 39, 1118-1126. (e) Gao, P.; Guo, W.; Xue, J.; Zhao, Y.; Yuan, Y.; Xia, Y.; Shi, Z. J. Am. Chem. Soc. 2015, 137, 12231-12240. 